\title{
Factors Affecting Customer Satisfaction with the Bus Service Quality of Phan Thiet Automobile Transport Cooperative
}

\author{
Luong My Linh ${ }^{1}$, Nguyen Quoc Nghi ${ }^{2}$, Dinh Hoang Anh Tuan ${ }^{1}$ \\ ${ }^{1}$ Phan Thiet University, ${ }^{2}$ Can Tho University, Vietnam \\ Corresponding Author: Luong My Linh
}

\begin{abstract}
This study aims to determine the factors influencing customer satisfaction with the bus service quality of Phan Thiet Automobile Transport Cooperative. Research data are collected from 290 customers who regularly use bus services of Phan Thiet Automobile Transport Cooperative. Applying the exploratory factor analysis and multivariate linear regression, the research results indicate factors positively affecting customer satisfaction with bus service quality are trust, assurance, empathy, traffic culture, perceived value, quality of the station, and tangible facilities. In which, the perceived value puts the most impact on customer satisfaction with the bus service quality of Phan Thiet Automobile Transport Cooperative.
\end{abstract}

Keywords: satisfaction, bus service, customer.

\section{PROBLEM STATEMENT}

Modern life allows people to have higher income and living standards, this leads to high requirements on the product/service quality. Accordingly, the demands for services such as food, entertainment, transportation, etc. significantly improved. Especially, traveling is an essential demand in modern society. In recent years, passenger transport services have developed rapidly to meet the travel demands, especially bus services in urban areas. Using buses brings certain benefits for individuals and the environment; meanwhile, people in urban areas rarely use buses. Most customers tend to choose private vehicles over buses due to their inconveniences, such as long waiting times, jostling, poor service, and low-quality facilities. This significantly affects the customer's satisfaction and acceptance to continue using the service in the long term. Within the above context, Phan Thiet Automobile Transport Cooperative has constantly improved the quality of customer service and considered customer satisfaction as the top priority. Therefore, identifying affecting factors to customer satisfaction and proposing solutions to improve service quality will be the key to find out ways to enhance bus service quality of Phan Thiet Automobile Transport Cooperative.

\section{THEORETICAL FRAMEWORK AND RESEARCH HYPOTHESES}

Referring to the concept of satisfaction, Bachelet (1992) considers customer satisfaction as the customer's emotional response to their experiences with a product or a service. Customer satisfaction is the expectation before and after purchasing a product or service (Oliver, 1997). According to Zeithaml and Bitner (2000), customer satisfaction is the customer's evaluation of a product or service that has met their needs and expectations. Kotler and Keller (2006) have defined customer satisfaction as the degree of a person's sensory state resulting from comparing the results obtained from consuming a product/ service with their expectations. The level of satisfaction depends on the difference 
Luong My Linh et.al. Factors affecting customer satisfaction with the bus service quality of phan thiet automobile transport cooperative.

between the results received and the expectations. If the actual results are lower than expected, the customers are not satisfied; if the actual results are commensurate with the expectation, the customers are satisfied; if the actual results are higher than expected, the customers are highly satisfied. Zeithalm and Bitner (2000) argued that customer satisfaction is affected by many factors such as product quality, service quality, price, situations, and personal factors. In the service industry, service quality is an essential factor that strongly influences customer satisfaction.

Based on the literature review and group discussions (qualitative research), the study proposes seven factors that are likely to affect customer satisfaction with the quality of bus service of Phan Thiet Automobile Transport Cooperative.

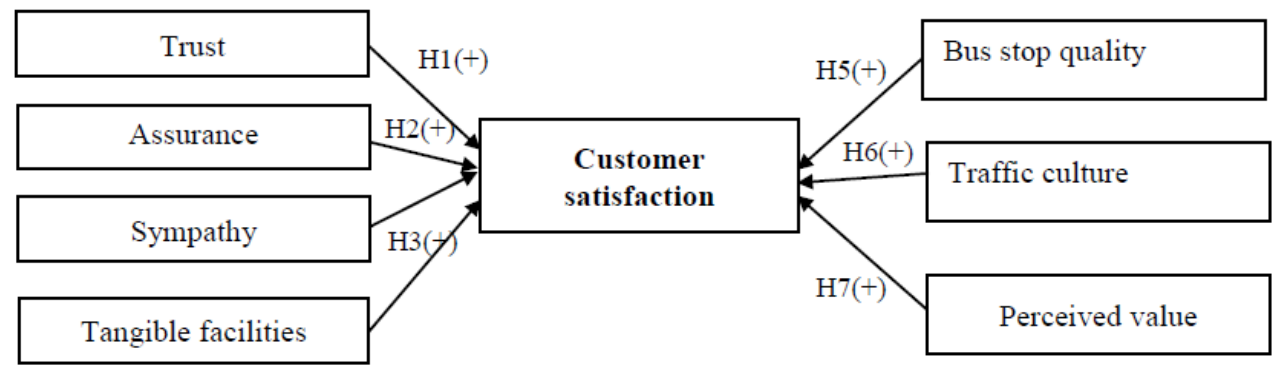

Figure 1: Proposed research method

From the above model, the research hypotheses are as follows: H1: Trust positively affects customer satisfaction with bus services. H2: Assurance has a positive influence on customer satisfaction with bus services. H3: Empathy positively impacts customer satisfaction with bus services. H4: Tangible facilities positively affect customer satisfaction with bus services. H5: Bus stop quality beneficially affects customer satisfaction with bus services. H6: Traffic culture positively influences customer satisfaction with bus services. H7: Perceived value has a positive influence on customer satisfaction with bus services.

Table 1: Interpretation of observed variables in the research model

\begin{tabular}{|c|c|c|}
\hline Sign & Observed variables & References resource \\
\hline & Trust & \\
\hline TR1 & The bus follows the route, schedule, and frequency as announced. & \multirow{5}{*}{ Kian et al. (2012), Nghi (2014) } \\
\hline TR2 & The information about time, schedule, and frequency is adequate and easy to understand. & \\
\hline TR3 & High level of safety and hygiene. & \\
\hline TR4 & The service fee is the same as in the price list. & \\
\hline \multirow[t]{2}{*}{ TR5 } & Drivers follow traffic rules. & \\
\hline & Assurance & \\
\hline AS1 & The staff is always polite to customers. & \multirow{3}{*}{ Kian et al. (2012), Nghi (2014) } \\
\hline AS2 & The staff cares about preserving customers' wealth and property. & \\
\hline \multirow[t]{2}{*}{ AS3 } & Customers always feel safe when using the service. & \\
\hline & Sympathy & \\
\hline SY1 & $\begin{array}{l}\text { The staff arranges seats for priority groups: the elderly, children, pregnant women, the } \\
\text { disabled. }\end{array}$ & \multirow{3}{*}{ Kian et al. (2012), Nghi (2014) } \\
\hline SY2 & Monthly tickets can be purchased easily and conveniently. & \\
\hline \multirow[t]{2}{*}{ SY3 } & The staff is always happy to show care for customers. & \\
\hline & Tangible facilities & \\
\hline TF1 & The equipment on the bus is in good condition. & \multirow{3}{*}{$\begin{array}{l}\text { Chow and Luk (2005), Kian et al. } \\
\text { (2012) }\end{array}$} \\
\hline TF2 & Equipment is neatly arranged. & \\
\hline \multirow[t]{2}{*}{ TF3 } & The staff's dress code is professional. & \\
\hline & Bus stop quality & \\
\hline SQ1 & Bus stops have a convenient location for waiting and picking up buses. & \multirow{4}{*}{ Kian et al. (2012), Nghi (2014) } \\
\hline SQ2 & Bus stops are clean. & \\
\hline SQ3 & Bus stops have sunshades and safe seats. & \\
\hline \multirow[t]{2}{*}{ SQ4 } & All bus stops have clear route instructions. & \\
\hline & Traffic culture & \\
\hline TC1 & $\begin{array}{l}\text { There are preferential policies for people with disabilities, the elderly, women, and } \\
\text { children. }\end{array}$ & \multirow{3}{*}{ Kian et al. (2012), Nghi (2014) } \\
\hline TC2 & Staff respect customers and behave politely. & \\
\hline TC3 & The bus service reflects the city's characteristics. & \\
\hline
\end{tabular}


Luong My Linh et.al. Factors affecting customer satisfaction with the bus service quality of phan thiet automobile transport cooperative.

\begin{tabular}{|l|l|l|}
\hline \multicolumn{2}{|l|}{ Table 1 Continued... } \\
\cline { 1 - 2 } & Perceived value & \multirow{2}{*}{ Kian et al. (2012), Nghi (2014) } \\
\hline PV1 & The ticket price is commensurate with the quality of service received. & \\
\hline PV2 & The ticket price is commensurate with the expected service quality. & \\
\hline PV3 & Ticket prices do not change when gasoline prices increase. & \multirow{2}{*}{ Kian et al. (2012), Nghi (2014) } \\
\hline & Satisfaction & \\
\hline SA1 & Satisfied with the service process. & \\
\hline SA2 & Satisfied with the responsiveness. & \\
\hline SA3 & Satisfied with the service quality. & \\
\hline SA4 & Satisfied with the value received from the service. &
\end{tabular}

\section{RESEARCH METHODOLOGY}

The hypothesis test is carried out in a three-step order as follows: Step 1: Use Cronbach's alpha coefficient to test the degree of internal correlation between observed variables. Step 2: Use exploratory factor analysis (EFA) to evaluate the convergent and discriminant validity of each observed variable. Step 3: Use multivariable linear regression to point out the influencing factors and the influence level of each factor within customer satisfaction.

According to Tho (2011), the sample size needed for the study depends on several factors such as the data analysis method and the required reliability. Hair et al. (1998) suggested that to apply EFA, the sample size should be at least 50 and the best could be 100. The observation/ measurement ratio should reach $5 / 1$, meaning that one measure needs at least five observations. In particular, the proposed research model includes 28 observed variables, so the required minimum sample size is $28 \times 5=140$. The study has surveyed 290 customers regularly using bus services of Phan Thiet Automobile Transport Cooperative. Therefore, the collected data ensures a high implementation level of the research model.

\section{RESEARCH RESULTS AND DISCUSSION}

To test the research model of factors affecting customer satisfaction with bus services of Phan Thiet Automobile Transport Cooperative, the study uses the SPSS software to support the analysis process. The test results are presented in the following order:

\subsection{Test the reliability of scales}

The study uses Cronbach's alpha coefficient to test the reliability of the scales. The test results in table 2 show that all scales have high Cronbach's alpha values (> 0.7). The corrected item-total correlation of variables is greater than 0.3 , so no variable is excluded from the research model (Nunnally, 1978; Peterson, 1994; Slater, 1995). Therefore, all observations are satisfactory and can be included in the exploratory factor analysis.

\begin{tabular}{|c|c|c|c|}
\hline Factor & $\begin{array}{l}\text { Number of } \\
\text { observed } \\
\text { variables }\end{array}$ & $\begin{array}{l}\text { Min } \\
\text { corrected } \\
\text { item-total } \\
\text { correlation }\end{array}$ & $\begin{array}{l}\text { Cronbach's } \\
\text { alpha }\end{array}$ \\
\hline Trust & 5 & 0.469 & 0.805 \\
\hline Assurance & 3 & 0.470 & 0.701 \\
\hline Sympathy & 3 & 0.616 & 0.801 \\
\hline Tangible facilities & 3 & 0.618 & 0.793 \\
\hline Bus stop quality & 4 & 0.551 & 0.782 \\
\hline Traffic culture & 3 & 0.645 & 0.817 \\
\hline Perceived value & 3 & 0.574 & 0.775 \\
\hline Satisfaction & 4 & 0.487 & 0.783 \\
\hline
\end{tabular}

\subsection{Exploratory factor analysis (EFA)}

The proposed research model requires the exploratory factor analysis to perform twice with independent factors and the dependent factor. The EFA for independent scales achieved the following results: (1) Factor loading value of scales > 0.5 . (2) Suitability test of the model $(0.5<$ $\mathrm{KMO}=0.742<1.0$ ). (3) Bartlett's test on correlation of observed variables (Sig. = $0.00<0.05$ ). (4) Total variance explained $=$ $66.7 \%>50 \%$. Hence, the observed variables achieve discriminant and convergent validity (Hair et al., 1998). Thereby, 7 independent factors are created from 26 observed variables, there is no disturbance among variables, so the factors' names remain the same. Similarly, the EFA results of the Satisfaction scale achieves the 
Luong My Linh et.al. Factors affecting customer satisfaction with the bus service quality of phan thiet automobile transport cooperative.

following values: (1) Factor loading > 0.5; (2) Testing the model's suitability $(0.5<$ $\mathrm{KMO}=0.776<1.0$ ). (3) Bartlett's test on correlation of observed variables (Sig. = $0.00<0.05)$. (4) Total variance explained $=$ $60.92 \%>50 \%$. The observed variables achieve discriminant and convergent validity (Hair et al., 1998). Therefore, this factor has no variable disturbance, so its name remains the same as in the proposed research model.

Table 3: Exploratory factor analysis test result

\begin{tabular}{|l|l|l|}
\multicolumn{4}{c}{ Table 3: Exploratory factor analysis test result } \\
\hline Sign & Observed variables & Factor \\
\hline TR & $\begin{array}{l}\text { 5 variables: TR1, TR2, TR3, TR4, } \\
\text { TR5 }\end{array}$ & Trust \\
\hline AS & 3 variables: AS1, AS2, AS3 & Assurance \\
\hline SY & 3 variables: SY1, SY2, SY3 & Sympathy \\
\hline TF & 3 variables: TF1, TF2, TF3 & $\begin{array}{l}\text { Tangible } \\
\text { facilities }\end{array}$ \\
\hline SQ & 4 variables: SQ1, SQ2, SQ3, SQ4 & Bus stop quality \\
\hline TC & 3 variables: TC1, TC2, TC3 & Traffic culture \\
\hline PV & 3 variables: PV1, PV2, PV3 & Perceived value \\
\hline SA & 4 variables: SA1, SA2, SA3, SA4 & Satisfaction \\
\hline \multicolumn{2}{|c|}{ Source: Survey data, 2021 } \\
\hline
\end{tabular}

\subsection{Multivariate linear regression}

Before testing the model, the study implements the exploratory testing on the regression model through the VIF and Durbin-Watson tests. The results show that the Durbin-Watson value of the model is 1.777, which means the model does not have autocorrelation (Nam, 2008). Besides, the variation inflation factor (VIF) of independent variables is much smaller than 4 , so there is no multicollinearity (Trong and Ngoc, 2008).

The analysis in table 4 shows that the significance level of the model (Sig.F $=$ 0.00 ) is much smaller than $\alpha=5 \%$, so the regression model is significant. This means there is at least one independent variable that affects customer satisfaction with bus service quality. The adjusted $\mathrm{R}^{2}=44.5 \%$ meaning that $44.5 \%$ of the variation of the "customer satisfaction with bus service quality" factor is explained by independent factors included in the model.

Table 4: Multivariate linear regression test result

\begin{tabular}{|l|l|l|l|l|}
\hline Factor & Standardize coefficient & Significance level (Sig.) & Variance inflation factor (VIF) & Hypothesis \\
\hline Trust & 0.143 & 0.002 & 1.141 & H1: accepted \\
\hline Assurance & 0.144 & 0.002 & 1.130 & H2: accepted \\
\hline Sympathy & 0.180 & 0.000 & 1.281 & H3: accepted \\
\hline Tangible facilities & 0.170 & 0.001 & 1.265 & H4: accepted \\
\hline Bus stop quality & 0.127 & 0.007 & 1.162 & H5: accepted \\
\hline Traffic culture & 0.113 & 0.016 & 1.131 & H6: accepted \\
\hline Perceived value & 0.339 & 0.000 & 1.198 & H7: accepted \\
\hline Adjusted R & & & 0.445 \\
\hline Durbin-Watson stat & & & 1.777 \\
\hline Sig.F & & & 0.000 \\
\hline
\end{tabular}

Based on the results in table 4 , all seven factors in the model are statistically significant at the 5\% level and positively correlated with customer satisfaction. In other words, trust, assurance, sympathy, tangible facilities, bus stop quality, traffic culture, and perceived value positively affect customer satisfaction with the bus service quality of Phan Thiet Automobile Transport Cooperative. In which, the perceived value has the strongest impact on customer satisfaction. It shows that when using bus services, customers are concerned about the following criteria: The ticket price is commensurate with the quality of the service received; The ticket price is commensurate with the expected service quality; The ticket price does not change when gasoline price increases. Besides, sympathy and tangible facilities are also focused on. These findings are a helpful scientific basis for Phan Thiet Automobile Transport Cooperative to refer to and make appropriate action programs to improve service quality and customer satisfaction.

\section{CONCLUSION}

Overall, the research has achieved the set goals to identify the factors impacting customer satisfaction with the bus service quality of Phan Thiet Automobile Transport Cooperative. The factors of trust, 
assurance, empathy, tangible facilities, bus stop quality, traffic culture, and perceived value positively affect customer satisfaction with bus service quality. In which, perceived value is the most significant factor that has the strongest influence on customer satisfaction. Therefore, some managerial implications are proposed to improve customer satisfaction with the bus service quality of Phan Thiet Automobile Transport Cooperative as follows: Firstly, the most priority is to enhance the perceived value of customers and improve the service quality. Secondly, sympathy is an essential factor constituting the service quality. Thus, administrators should pay attention to building trust for customers. Thirdly, administrators need to improve responsiveness. Fourthly, administrators should focus on tangible facilities which help improve the customers' perceived value.

\section{Acknowledgement: None}

\section{Conflict of Interest: None}

\section{Source of Funding: None}

\section{REFERENCES}

1. Bachelet, D. (1992). Measuring Satisfaction or the Chain, the Tree, and the Nest. In Esomar Marketing Research Congress (pp. 229-229). Esomar.

2. Chow, C. C., \& Luk, P. (2005). A strategic service quality approach using analytic hierarchy process. Managing service quality: an international journal, 15(3), 278-289.

3. Hair, J. F., Tatham, R. L., Anderson, R. E., \& Black, W. (1998). Multivariate Data Analysis ( $5^{\text {th }}$ ed.). New Jersey: PrenticeHall, Inc.
4. Kian, T. P., Latiff, K. B., \& Fong, S. W. L. (2012). The impact of 'QUALBUS' towards customer satisfaction in public transportation. In 2nd International Conference on Management Proceeding (pp. 45-59).

5. Kotler, P., \& Keller, K. L. (2006). Marketing Management $\left(12^{\text {th }}\right.$ ed.). New Jersey: Pearson Prentice Hall.

6. Nam, M. V. (2008). Econometrics. Hanoi: Culture and Information Publishing House.

7. Nghi, N. Q. (2014). Factors affecting the level of customer satisfaction towards the high-quality vehicle services. (2014), 43-48.

8. Nunnally, J. (1978). Psychometric Theory. New York: McGraw-Hill.

9. Oliver, R. L. (2010). Satisfaction: A Behavioral Perspective on the Consumer, 2. bask1. London: ME Sharpe.

10. Peterson, R. (1994). A meta-analysis of Cronbach's coefficient alpha. Journal of Consumer Research, 21(2), 381-391.

11. Slater, S. (1995). Issues in Conducting Marketing Strategy Research. Journal of Strategic, 3(4), 257-270.

12. Tho, N. D. (2011). Methods of scientific research in business. Hanoi: Publisher Socialist Labor.

13. Trong, H., \& Ngoc, C. N. M. (2008). Data analysis with SPSS. Hanoi: Statistical Publishing House.

14. Zeithaml, V. A., \& Bitner, M.J. (2000). Services Marketing: Integrating customer focus across the firm ( $2^{\text {nd }}$ ed.). Boston: McGraw-Hill.

How to cite this article: Linh LM, Nghi NQ, Tuan DHA. Factors affecting customer satisfaction with the bus service quality of phan thiet automobile transport cooperative. International Journal of Research and Review. 2021; 8(10): 213-217. DOI: https://doi.org/10. 52403/ijrr.20211027 